\title{
Hyperphosphorylation of DegU cancels CcpA-dependent catabolite repression of rocG in Bacillus subtilis
}

\author{
Kosei Tanaka', Kana Iwasaki ${ }^{2}$, Takuya Morimoto ${ }^{3,4}$, Takatsugu Matsuse ${ }^{2}$, Tomohisa Hasunuma' ${ }^{1}$, Shinji Takenaka ${ }^{1,2}$,
} Onuma Chumsakul ${ }^{4}$, Shu Ishikawa ${ }^{4}$, Naotake Ogasawara ${ }^{4}$ and Ken-ichi Yoshida ${ }^{1,2^{*}}$

\begin{abstract}
Background: The two-component regulatory system, involving the histidine sensor kinase DegS and response regulator DegU, plays an important role to control various cell processes in the transition phase of Bacillus subtilis. The degU32 allele in strain 1A95 is characterized by the accumulation of phosphorylated form of DegU (DegU-P).

Results: Growing 1A95 cells elevated the pH of soytone-based medium more than the parental strain 168 after the onset of the transition phase. The rocG gene encodes a catabolic glutamate dehydrogenase that catalyzes one of the main ammonia-releasing reactions. Inactivation of rocG abolished 1A95-mediated increases in the pH of growth media. Thus, transcription of the rocG locus was examined, and a novel 3.7-kb transcript covering sivA, rocG, and rocA was found in 1 A95 but not 168 cells. Increased intracellular fructose 1,6-bisphosphate (FBP) levels are known to activate the HPr kinase HPrK, and to induce formation of the P-Ser-HPr/CcpA complex, which binds to catabolite responsive elements (cre) and exerts CcpA-dependent catabolite repression. A putative cre found within the intergenic region between sivA and rocG, and inactivation of ccpA led to creation of the 3.7-kb transcript in 168 cells. Analyses of intermediates in central carbon metabolism revealed that intracellular FBP levels were lowered earlier in 1A95 than in 168 cells. A genome wide transcriptome analysis comparing 1A95 and 168 cells suggested similar events occurring in other catabolite repressive loci involving induction of IctE encoding lactate dehydrogenase.

Conclusions: Under physiological conditions the 3.7-kb rocG transcript may be tightly controlled by a roadblock mechanism involving P-Ser-HPr/CcpA in 168 cells, while in 1 A95 cells abolished repression of the 3.7-kb transcript. Accumulation of DegU-P in 1 A95 affects central carbon metabolism involving IctE enhanced by unknown mechanisms, downregulates FBP levels earlier, and inactivates HPrK to allow the 3.7-kb transcription, and thus similar events may occur in other catabolite repressive loci.
\end{abstract}

Keywords: Bacillus subtilis, Two-component regulatory system, Catabolite repression, Transcription, Metabolites

\section{Background}

Bacteria possess two-component regulatory systems comprising environmental sensor histidine kinases and cognate response regulators that are involved in adaptation to various chemical, physical, and physiological stimuli [1]. Following stimulation, autophosphorylation of specific sensor histidine kinases leads to transfer of a phosphoryl

\footnotetext{
* Correspondence: kenyoshi@kobe-u.ac.jp

'Organization of Advanced Science and Technology, Kobe University, Kobe, Hyogo, Japan

${ }^{2}$ Department of Agrobioscience, Kobe University, Kobe, Hyogo, Japan
}

Full list of author information is available at the end of the article group to cognate transcriptional response regulators that control respective target genes.

In Bacillus subtilis, the DegS-DegU two-component regulatory system controls various processes during the transition from exponential to stationary growth phases, including the expression of extracellular degradative enzymes and late competence genes [2]. The phosphorylated form of DegU (DegU-P) induces a number of genes, whereas the unphosphorylated form also stimulates transcription of comK, which encodes the competence transcription factor $[3,4]$. In addition, DegU-P negatively regulates genes of the sigma factor SigD regulon,

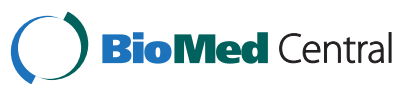

(c) 2015 Tanaka et al.; licensee BioMed Central. This is an Open Access article distributed under the terms of the Creative Commons Attribution License (http://creativecommons.org/licenses/by/4.0), which permits unrestricted use, distribution, and reproduction in any medium, provided the original work is properly credited. The Creative Commons Public Domain Dedication waiver (http://creativecommons.org/publicdomain/zero/1.0/) applies to the data made available in this article unless otherwise stated. 
which are involved in motility, chemotaxis, and autolysin production $[2,5,6]$. In addition, the DegS-DegU system is modulated by two regulatory genes, $\operatorname{deg} Q$ and $\operatorname{deg} R$, which encode small polypeptides of 46 and 60 amino acids, respectively [7]. In wild-type strains, DegQ enhances phosphorylation of DegU [8], whereas DegR protects DegU-P from dephosphorylation [9]. In contrast in the standard laboratory strain 168 , due to a mutation in the -10 region ( $\mathrm{T}-10$ to $\mathrm{C}$ ) of its cognate promoter, $\operatorname{deg} Q$ is not efficiently transcribed, and DegU-P does not accumulate as in wild-type strains [10].

In the previous studies, mutations in DegU led to overproduction of extracellular degradative enzymes and correlated with the loss of natural competence for DNA uptake, the lack of flagella synthesis, filamentous morphology, and higher sporulation efficiency in the presence of glucose [11-13]. Among these mutations, the allele degU32 in strain 1A95 has an amino acid substitution at position 12 [14]. This mutation increases the stability of DegU-P sevenfold, and amplifies DegU-P dependent gene expression even with the genetic background of strain 168 [13]. Extracellular proteomic studies of the degU32 mutant indicated that 13 extracellular enzymes are overproduced and that eight proteins of motility and cell-wall turnover were significantly downregulated, including five SigD-dependent proteins [15]. The subsequent transcriptome analysis confirmed similar induction and repression of the known DegU-P and DegU dependent genes, respectively [16].

Bacterial carbon catabolite repression (CCR) is a global regulatory mechanism that occurs in the presence of a preferred carbon source and represses genes involved in metabolism of other minor carbon sources, coordinating metabolic responses to efficient carbon and energy sources. In B. subtilis, CCR occurs primarily at the transcription level and involves phosphorylation of CcpA and HPr at the Ser-46 residue (P-Ser-HPr) [17]. Preferred carbon sources such as glucose are readily converted into glycolytic intermediates, including fructose-1,6-bisphosphate (FBP), and the accumulation of intracellular FBP stimulates HPr kinase/phosphatase, which phosphorylates HPr to P-Ser-HPr. CcpA is a member of the LacI/GalR family of transcriptional regulators, which are synthesized constitutively irrespective of the presence or absence of repressing sugars. The CcpA/P-Ser-HPr complex is formed only in response to P-Ser-HPr, and exerts sitespecific DNA-binding activity with 14-bp cis-acting palindromic sequences that are known as catabolite responsive elements (cre). Because DNA binding of CcpA/P-Ser-HPr interferes with both initiation and elongation of target gene transcription under CCR, CcpA/P-Ser-HPr functions as a classical repressor and a transcriptional roadblock. In contrast, $\mathrm{HPr}$ originally functions as the energy coupling protein of the phosphotransferase system (PTS), which mediates carbohydrate transport following phosphorylation of the His-15 residue.

B. subtilis expresses the two glutamate dehydrogenase genes $g u d B$ and $\operatorname{rocG}$. In the standard laboratory strain 168 and its derivatives, $\operatorname{gudB}$ is a cryptic gene with a short repeat within the coding region, whereas in the wild-type B. subtilis strains this gene encodes an intact enzyme [18]. Potentially, the ancestral $\operatorname{gudB}$ gene became inactive during domestication under laboratory conditions. In contrast, RocG functions as an active catabolic glutamate dehydrogenase and is induced in the presence of arginine, ornithine, or proline following transcriptional activation of the SigL-dependent promoter and enhancement by the transcription factor RocR [19]. RocG is also regulated by CcpA-dependent CCR, involving a cre situated just downstream of the rocG promoter [20]. Moreover, RocG is involved in ammonia-releasing reactions during the production of the Japanese food natto, which is produced by fermentation of soybeans using strains of $B$. subtilis natto that are equivalent to wild-type B. subtilis strains [18].

As described above, 1A95 cells carry the degU32 mutation on the genetic background of the laboratory strain 168. In the present study, we noticed that the $\mathrm{pH}$ of soytone-based medium significantly increased during growth of 1A95 cells after the onset of the transition phase. Thus, we speculated that this change in $\mathrm{pH}$ reflects ammonia release following glutamate degradation by RocG. Subsequent investigations of transcription in the rocG locus revealed a novel transcript in 1A95 cells. Further experiments indicated that hyperphosphorylation of DegU may proactively abolish CcpA-dependent $\mathrm{CCR}$, modulating the regulatory network involving intracellular metabolites and phosphorylation of HPr.

\section{Results}

The degU32 mutation led to elevated $\mathrm{pH}$ of growth medium following activation of rocG encoding glutamate dehydrogenase

During growth of B. subtilis strains in soytone-glucose medium, pH levels decreased to around 5.5 prior to transition from the logarithmic to the stationary phase, and then increased during the stationary phase (Figure 1). However, $\mathrm{pH}$ levels gradually increased to around 6.5 and no higher than 7.0 during growth of the laboratory standard strain 168, whereas the 1A95 (degU32) strain significantly elevated $\mathrm{pH}$ to almost 8.0.

rocG encoding glutamate dehydrogenase mediates ammonia-releasing reactions during secondary natto fermentation [18]. Thus, we suspected that ammonia may contribute to increases in the $\mathrm{pH}$ of growth media, and observed ammonia accumulation in the culture medium of 1A95 cells (Figure 1). Inactivation 

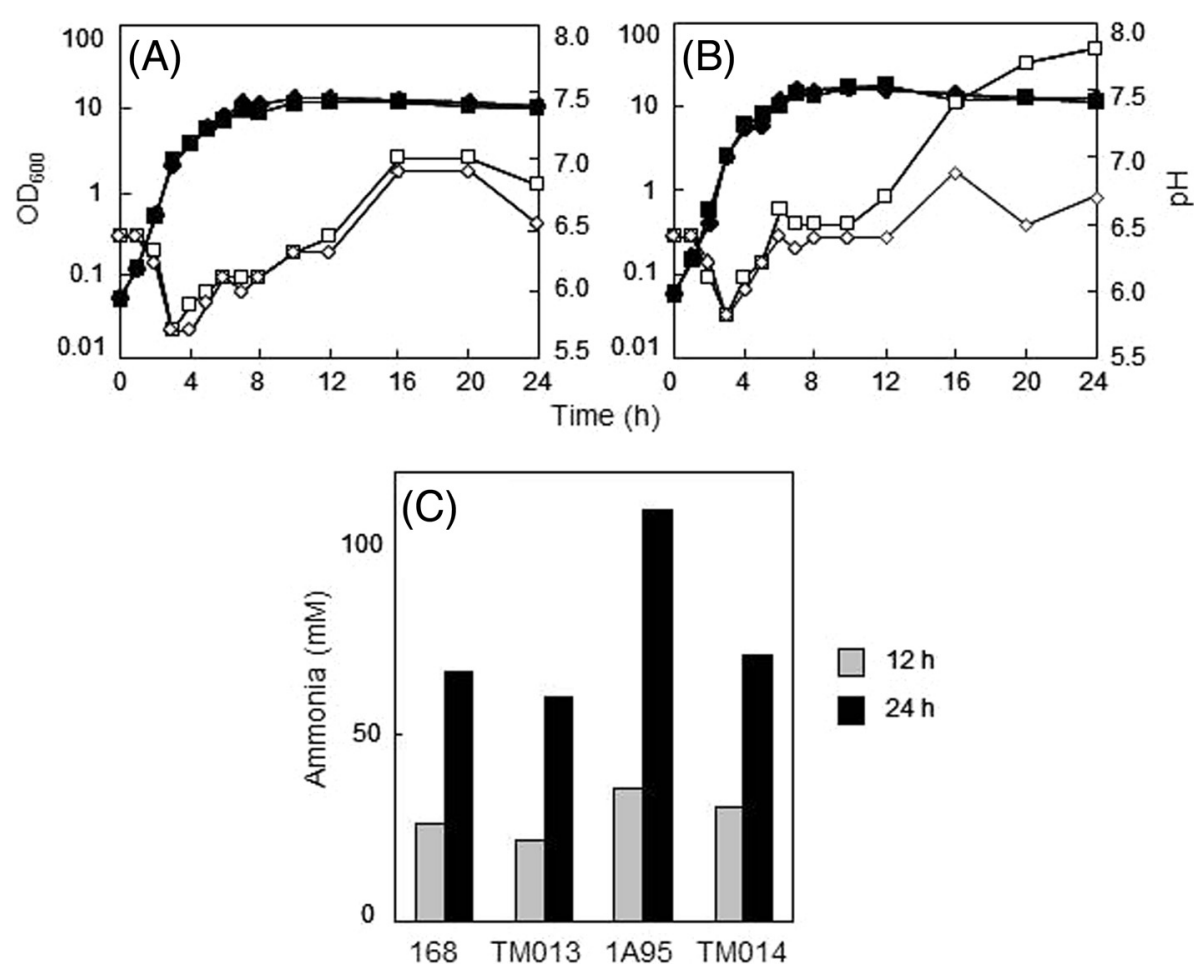

Figure 1 Involvement of rocG in elevated pH and ammonia levels in the growth medium of strain 1 A95 (degU32). (A) Growth curves of B. subtilis strains 168 (closed squares) and TM013 (rocG.:cat, closed diamonds) in the soytone-glucose medium; pH values are indicated for 168 (open squares) and TM013 (open diamonds) cultures. (B) Growth curves of strains 1A95 (degU32, closed squares) and TM014 (degU32 rocG::cat, closed diamonds) in the soytone-glucose medium; pH values are indicated for 1 A95 (open squares) and TM014 (open diamonds) cultures. (C) Levels of ammonia in media at 12 (gray bars) and 24 (black bars) h after inoculation.

of rocG in the 168 strain only had a slight effect on $\mathrm{pH}$ and ammonia accumulation (Figure $1 \mathrm{~A}$ and $\mathrm{C}$, strain TM013). However, inactivation of rocG in $1 \mathrm{~A} 95$ cells prevented increases in $\mathrm{pH}$ and accumulation of ammonium, which remained at similar levels to those observed in 168 cells (Figure 1B and C, strain TM014). These data indicate that degU32 contributes to increases in $\mathrm{pH}$, potentially by enhancing RocG-mediated release of ammonia.

\section{Cells expressing degU32 produced a novel 3.7-kb transcript containing rocG}

Total RNAs were extracted from cells during the transition from logarithmic to stationary phases, just prior to $\mathrm{pH}$ increases (Figure 1B). In subsequent northern blotting analyses (Figure 2), three mRNA species containing roc $G$ were detected in 1A95 cells under low-stringency conditions, with sizes of 5.0, 3.7, and $1.5 \mathrm{~kb}$ (Figure 2A). Control of rocG by RocR reportedly activates the SigLdependent promoters for rocABC, rocDEF, and rocG in the presence of arginine metabolites such as citrulline and ornithine [19-21]. Both 5.0- and 1.5-kb transcripts were detected in 168 cells, but were not present in TM016 cells (degU32 rocR::kan). These observations indicate probable dependence of these two transcripts on rock but not on $\operatorname{deg} U 32$, although further experiments were not performed on these transcripts because they were not detected under high-stringency conditions (see below). The signals for the $1.5-\mathrm{kb}$ transcript were rather exaggerated probably due to a synergistic effect of non-specific hybridization to 16S rRNA under the lowstringency conditions. In contrast, appearance of the 3.7-kb transcript depended solely on $\operatorname{deg} U 32$ in 1A95 and TM016 cells and was not present in strains 168 and TM015 (degU32::cat), indicating that this novel $3.7-\mathrm{kb}$ transcript may enhance the function of RocG in 1A95 cells.

The $3.7-\mathrm{kb}$ transcript was weakly but substantially detected under low-stringency conditions using either $\operatorname{siv} A$ (formerly yweA) or rocA probes in 1A95 and TM016 cells (Figure $2 \mathrm{~B}$ and $\mathrm{C}$ ), suggesting coverage of rocG, $\operatorname{siv} A$, and $r o c A$. A very strong $0.6-\mathrm{kb} \operatorname{siv} A$ transcript was observed in all four strains, suggesting transcription from a constitutive promoter upstream of $\operatorname{siv} A$ (Figure 2B). The probe for rocA detected another $1.5-\mathrm{kb}$ transcript in 168, 1A95, and TM015 cells, but not in TM016 cells, suggesting dependence on rocR (Figure 2C). Even under highstringency conditions, the $3.7-\mathrm{kb}$ transcript was clearly 


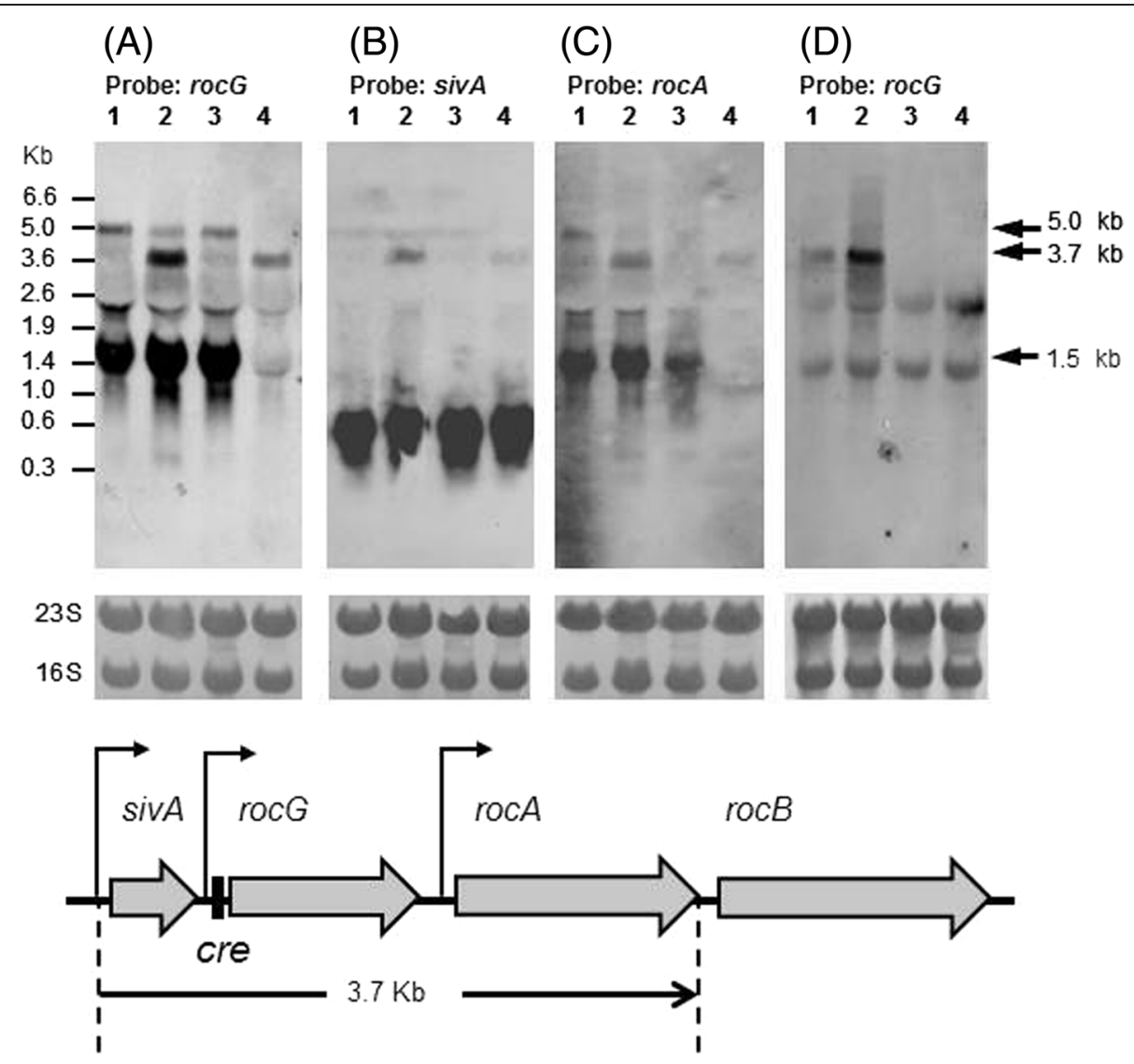

Figure 2 Northern blotting analyses of transcripts containing rocG, sivA, and rocA. RNAs were prepared from 168 (lane 1), 1A95 (degU32, lane 2), TM015 (degU32::cat, lane 3), and TM016 (degU32 rocR::kan, lane 4) cells for northern blotting analyses using probes for rocG (A), sivA (B), and rocA (C) transcripts under low-stringency conditions. (D) RNAs were prepared from 1 A95 (degU32, lane 1), TM016 (degU32 rocR::kan, lane 2), TM017 (sivA::pMutin2, lane 3), and TM018 (degU32 sivA::pMutin2, lane 4) cells for northern blotting analyses using probes for rocG transcripts under high-stringency conditions; rRNAs (23S and 16S) on membranes were visualized as a loading control using methylene blue staining. Gene organization of the rocG locus is shown at the bottom.

detected using the rocG probe in 1A95 and TM016 cells, but was absent after disruption of sivA in TM018 cells (degU32 sivA::pMutin2; Figure 2D). The 5.0- and 1.5-kb roc $G$ transcripts observed under low-stringency conditions (Figure 2A) were not detectable under high-stringency conditions in 1A95 cells (Figure 2D), suggesting that the $3.7-\mathrm{kb}$ transcript could be the major rocG transcript in $1 \mathrm{~A} 95$ cells and is dependent on degU32. Primer extension analyses revealed a transcription start site at 97 bases upstream of the translation start site of $\operatorname{sivA}$ (Figure 3). Thus, the corresponding promoter may comprise the -35 (TTTACT) and -10 (TAGATT) regions with a 17 -bp spacer and may be a typical SigA-dependent one. The constitutive $0.6-\mathrm{kb}$ transcript may be the main $\operatorname{siv} A$ transcript, and is produced independently of $\operatorname{deg} U 32$ or rocR (Figure 2B). Accordingly, the present northern analyses (Figure $2 \mathrm{~B}$ ) and a previous study indicate that transcription from the $\operatorname{siv} A$ promoter may be independent of both SigL and RocR [22].

\section{Control of the 3.7-kb rocG transcript by CcpA-dependent CCR}

A previous study indicated that rocG is regulated by CcpA-dependent CCR, involving a putative cre site in the intergenic region between $\operatorname{siv} A$ and $\operatorname{rocG}$ [20]. Moreover, the $\operatorname{siv} A$ transcript may be read through to cover downstream rocG [22]. CcpA-dependent CCR involves not only repression of transcriptional initiation at promoter sites but also a roadblock mechanism that aborts ongoing transcription [17]. Along with previous results, the present data suggest that the $3.7-\mathrm{kb}$ transcript is produced by transcription through the main $0.6-\mathrm{kb} \operatorname{siv} A$ and elongation to cover both rocG and rocA, and thus escapes CcpA-dependent CCR. Although a Rho-independent terminator $(\Delta \mathrm{G}=-16.90 \mathrm{kcal} / \mathrm{mol}$, Figure $3 C)$ is present and may terminate transcription from the $\operatorname{siv} A$ promoter, it may allow some read through. Moreover, CcpA-dependent CCR may arrest the read via the roadblock mechanism in 168 cells but not in 1A95 
(A)

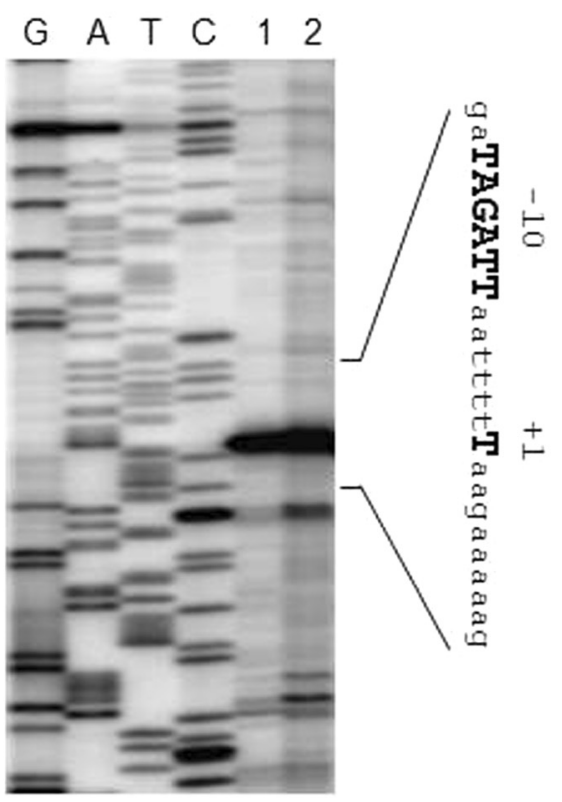

(B)

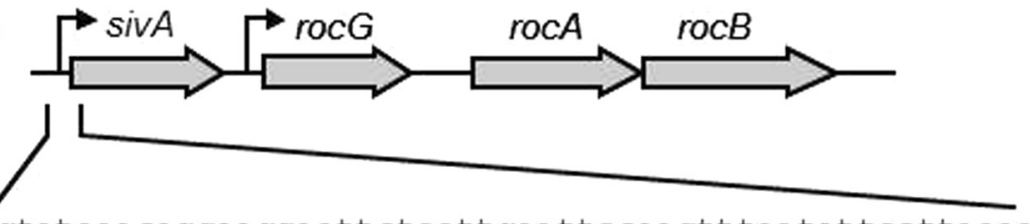

gtataa caggaaggaattctcattgaattccaagtt taatattccttaaa

$-35$

$-10$

$+1$

aaca TTTACT tccatggaaatgatga TAGATT aattt Taagaa

aagaactggtaattcgcgaattatgaaaagggcttttctgcagaggacgc

tctggccaaatt caa caatcaattagggggaaatgtcATGCTAAAAA

SivA orf

(C)

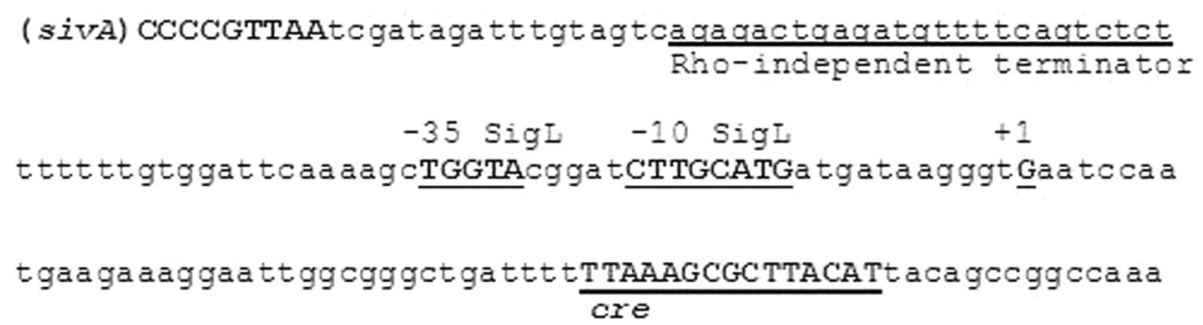

aaacaatgaggtgaaaagATGTCA (rocG)

Figure 3 The promoter and terminator regions of sivA. (A) Primer extension analyses of the sivA promoter region; RNAs were prepared from 168 (lane 1) and 1A95 (degU32, lane 2) cells, and were reverse transcribed to generate cDNAs corresponding to the $5^{\prime}$-terminus of sivA transcripts. Lanes $G, A, T$, and $C$ contained dideoxy sequencing ladders. The partial nucleotide sequence of the coding strand is shown on the right side, where the putative -10 region and the transcription start site $(+1)$ are shown in enlarged uppercase characters. (B) Schematic presentation of the sivA promoter region. The nucleotide sequence of the upper strand of the promoter region is shown, and putative -35 and -10 regions, the transcription start site $(+1)$, and the beginning of the sivA open reading frame are shown with enlarged uppercase characters. (C) Nucleotide sequence of the intergenic region between sivA and rocG. The C-terminal end of sivA, the Rho-independent terminator, SigL-dependent rocG promoter (+35 and -10 regions), its transcription start site $(+1)$, the cre site, and the $\mathrm{N}$-terminal end of rocG are indicated. 
cells. It was previously shown that $\operatorname{roc} A B C$ composed a single $5.0-\mathrm{kb}$ transcriptional unit depending on both SigL and RocR [23]. Another northern blotting analysis revealed that a $\operatorname{roc} B$ specific probe detected the $5.0-\mathrm{kb}$ transcript but failed to detect the $3.7-\mathrm{kb}$ one (Additional file 1: Figure S1). Recently an internal terminator was found just behind rocA $[24,25]$, and this terminator could function in this case to generate the $3.7-\mathrm{kb}$ transcript covering $\operatorname{siv} A, \operatorname{roc} G$, and $\operatorname{roc} A$. The SigL-dependent rocG promoter and its corresponding transcription start site are located upstream of the cre site [26]. Therefore, the CcpA-dependent roadblock might also control SigL-dependent rocG transcription.

When $с с p A$ was inactivated (ссрA::neo) in strain 168, the $3.7-\mathrm{kb}$ transcript containing $\operatorname{roc} G$ was produced as in $1 \mathrm{~A} 95$ cells (Figure 4; note that the $5.0-$ and $1.5-\mathrm{kb}$ transcripts were not detected under high-stringency conditions). These observations indicated that the $3.7-\mathrm{kb}$ transcript was repressed by CcpA-dependent CCR in 168 cells and was likely "induced" in the 1A95 (degU32) strain, allowing proactive abolition of the CcpA-dependent $\mathrm{CCR}$ roadblock at the $c r e$ in the intergenic region between $\operatorname{siv} A$ and rocG (Figure 3C). However, the $c c p A$ mutation in 168 produced an additional $2.7-\mathrm{kb}$ transcript that remains uncharacterized.

\section{Intracellular FBP levels were reduced earlier in degU32 mutant cells due to enhanced expression of IctE}

To investigate abolition of CcpA-dependent CCR in 1A95 (degU32) cells, intracellular intermediates of central carbon metabolism were determined by capillary electrophoresis-mass spectrometry (CE-MS) analysis and compared with those in 168 cells (Figure 5). FBP levels decreased during the growth in both strains, and the decrease occurred faster in 1A95 cells. Glucose 6phosphate (G6P) levels also decreased in 1A95. In contrast, 3-phosphoglyceric acid (3PG), phosphoenolpyruvate (PEP), and pyruvate (PYR) levels were consistently lower in 1A95 cells than in 168 cells. Thus, glycolysis might proceed more efficiently in 1A95 than in 168 cells, and the faster reduction in the FBP levels led to an earlier alleviation of CcpA-dependent CCR. On the other hand, in both strains, levels of intermediates of the pentose phosphate pathway, including 6-phosphogluconate (6PG), ribulose 5-phosphate (Ru5P), and sedoheptulose 7-phosphate (S7P), were generally lower than the glycolytic intermediates, such as G6P, FBP, and 3PG, nevertheless some significant effects of $\operatorname{deg} U 32$ were seen to lower the levels of intermediates in the pentose phosphate pathway. Potentially, glycolysis might consume glucose more efficiently in 1A95 cells, as reflected by lower levels of 6PG, Ru5P, and S7P.

Transcriptome analyses were performed to compare 168 and 1A95 during transition from the logarithmic to

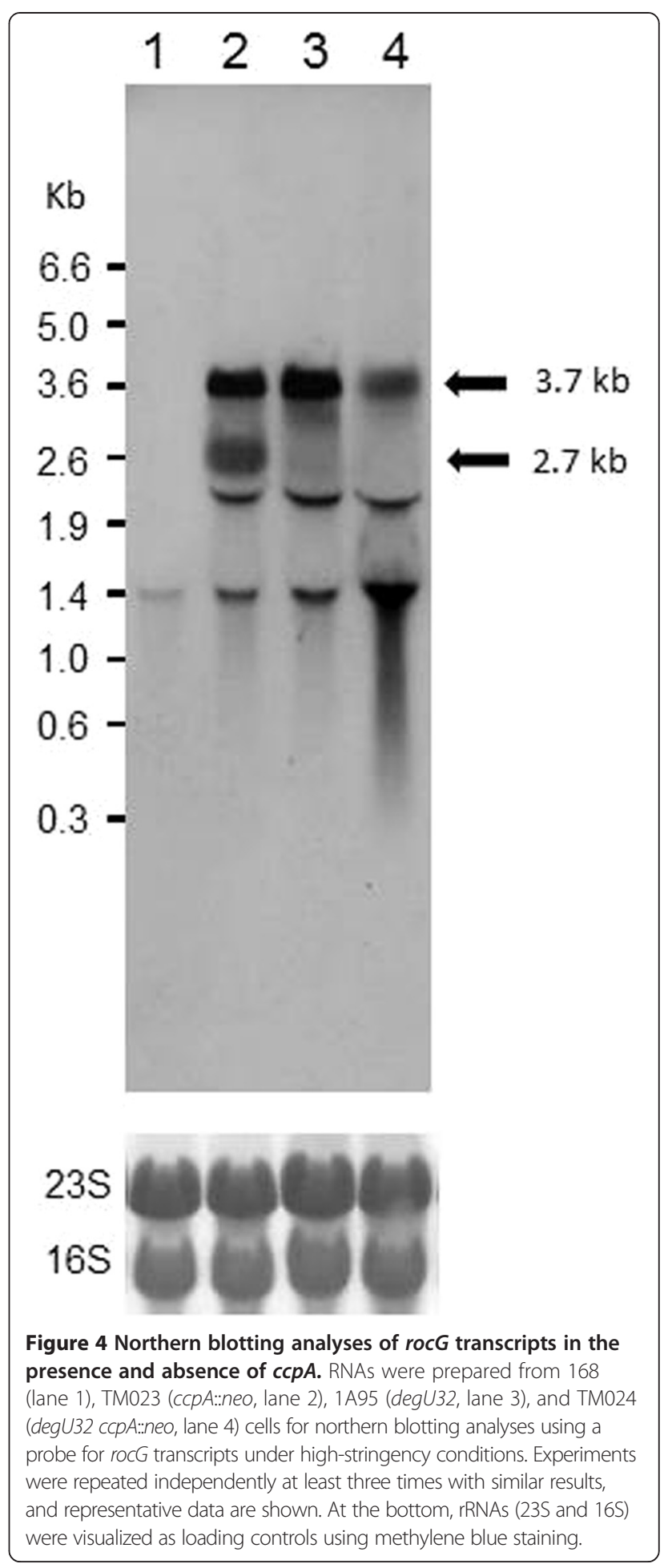

the stationary phase. Among 25 selected genes of glycolysis, pentose phosphate, and branching fermentation pathways for lactate, acetoin, and acetate production, lctE, ackA, and gntZ, were enhanced by 5.44-, 5.86-, and 4.53-fold, respectively, in 1A95 cells compared with 168 cells (Table 1). lctE for lactate dehydrogenase was 


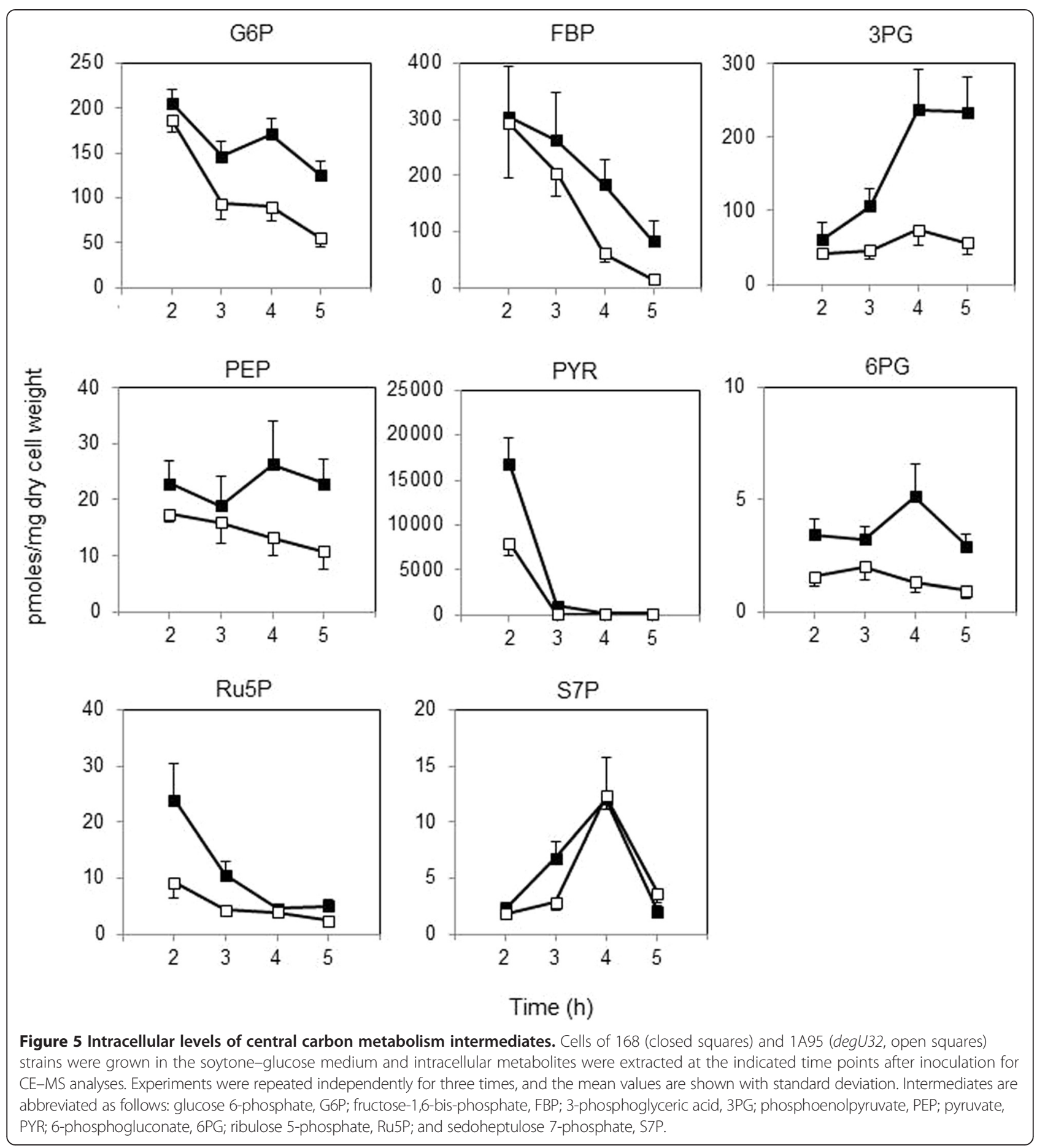

prominently expressed in 1A95 cells and its inactivation led to disappearance of the $3.7-\mathrm{kb}$ transcript containing rocG (Figure 6) and maintenance of high intracellular FBP levels (Figure 7). Thus, $\operatorname{deg} U 32$ in 1A95 cells may enhance the expression of $l c t E$ through unknown mechanisms. Because PYR is the end product of glycolysis, rapid clearance of PYR due to its conversion into lactate by lactate dehydrogenase (LctE) might accelerate glycolysis, and lower intracellular FBP levels might cancel CcpAdependent CCR earlier. gntZ for 6PG dehydrogenase is part of the gntRKPZ operon for gluconate catabolism [27], which is induced specifically in the presence of gluconate and repressed with glucose via CcpA-dependent CCR [28]. There is an additional promoter upstream of gntZ (within the gntP coding region), which allows transcription of gnt $Z$ independently [27]. Although this 
Table 1 Transcriptome analyses of 168 and $1 \mathrm{A95}$ cell $^{\mathrm{a}}$

\begin{tabular}{|c|c|c|c|}
\hline Gene $^{b}$ & Signal in 168 & Signal in $1 \mathrm{~A} 95$ & Ratio (1 A95/168) \\
\hline ptsG & 868.57 & 5437.79 & 6.26 \\
\hline$a c k A$ & 392.94 & 2301.16 & 5.86 \\
\hline IctE & 1031.06 & 5603.86 & 5.44 \\
\hline gntZ & 209.03 & 947.25 & 4.53 \\
\hline $\mathrm{sacP}$ & 194.83 & 680.86 & 3.49 \\
\hline dra & 405.07 & 1210.64 & 2.99 \\
\hline$y x k J$ & 339.75 & 991.7 & 2.92 \\
\hline resB & 802.05 & 2072.13 & 2.58 \\
\hline rbsC & 54.75 & 133.97 & 2.45 \\
\hline rocG & 220.35 & 470.1 & 2.13 \\
\hline $\mathrm{kdgA}$ & 87.12 & 161.59 & 1.85 \\
\hline rpe & 657.61 & 1190.12 & 1.81 \\
\hline$p d h A$ & 2110.16 & 3796.04 & 1.80 \\
\hline rbsk & 167.65 & 278.05 & 1.66 \\
\hline$p f k A$ & 2557.11 & 4158.71 & 1.63 \\
\hline rbsA & 94.2 & 153.12 & 1.63 \\
\hline rbsR & 178.33 & 280.61 & 1.57 \\
\hline pyk & 2613.65 & 4060.8 & 1.55 \\
\hline $\mathrm{lic} B$ & 137.4 & 210.68 & 1.53 \\
\hline $\mathrm{rbs} D$ & 55.17 & 83.13 & 1.51 \\
\hline $\operatorname{ccpC}$ & 369.74 & 534.18 & 1.44 \\
\hline cydA & 332.81 & 436.13 & 1.31 \\
\hline acuA & 364.04 & 452.95 & 1.24 \\
\hline tpiA & 3565.89 & 4427.84 & 1.24 \\
\hline eno & 4240.4 & 5052.53 & 1.19 \\
\hline $\operatorname{ccc} A$ & 417.01 & 476.84 & 1.14 \\
\hline xynP & 32.02 & 36.61 & 1.14 \\
\hline pgm & 5078.95 & 5724.25 & 1.13 \\
\hline yxjC & 81.09 & 91.33 & 1.13 \\
\hline iolB & 44.32 & 48.99 & 1.11 \\
\hline pgk & 5422.94 & 5971.13 & 1.10 \\
\hline$y w / F$ & 2421.27 & 2526.84 & 1.04 \\
\hline$z w f$ & 2672.83 & 2708.68 & 1.01 \\
\hline$f b a A$ & 5096.63 & 4798.53 & 0.94 \\
\hline gapA & 7210.27 & 6348.19 & 0.88 \\
\hline pta & 2607.11 & 2276.82 & 0.87 \\
\hline$a c O A$ & 62.03 & 53.74 & 0.87 \\
\hline tkt & 3921.21 & 3212.77 & 0.82 \\
\hline ywjH & 4166.18 & 3188.41 & 0.77 \\
\hline$f b p$ & 739.27 & 516.33 & 0.70 \\
\hline alss & 5558.12 & 3623.65 & 0.65 \\
\hline als $D$ & 6286.45 & 3471.86 & 0.55 \\
\hline
\end{tabular}

Table 1 Transcriptome analyses of 168 and 1 A95 cell ${ }^{\mathrm{a}}$ (Continued)

\begin{tabular}{llll}
\hline pgi & 5106.18 & 2565.71 & 0.50 \\
gapB & 258.35 & 99.25 & 0.38 \\
acsA & 1836.8 & 450.84 & 0.25
\end{tabular}

${ }^{\mathrm{a}}$ Detailed results are available in the ArrayExpress database [63] under accession number E-MTAB-2944.

bome representative genes under direct CcpA-dependent CCR [32], and selected genes (italic) of glycolysis, pentose phosphate, and branching fermentation pathways to lactate, acetoin, and acetate, are listed in descending order of ratio (1A95/168).

gntZ-specific transcription is not under CCR, it might be involved in the enhanced expression. ackA for acetate kinase is positively regulated by CcpA in the presence of glucose [29,30], involving either phosphorylated HPr or Crh [31]. Therefore, when FBP levels get lower, ackA was expected to be down regulated. But under the present conditions, ack $A$ was induced probably due to CodY function as discussed below.

\section{The degU32 allele affects global CcpA-dependent CCR}

As described above, expression of degU32 lowered intracellular FBP levels earlier, potentially reflecting an effect on global CcpA-dependent CCR. Accordingly, transcriptome analyses revealed that expression levels of some other genes that are regulated by CcpA-dependent CCR [32] were enhanced in 1A95 cells in the transition state (Table 1). Thus, ptsGHI, licRBCA, and deoR-dra-nupC$p d p$ were examined in specific northern blotting analyses using RNAs from transitioning cells grown in the soytone-glucose medium (Figure 8).

The ptsGHI operon encodes the glucose-specific PTS sugar transport system and is induced following interactions between the terminator immediately downstream of the promoter of $p t s G$ and the specific antiterminator GlcT, which is activated by glucose [33]. In a previous report, a putative cre site located upstream of the translation initiation point of $p t s G$ did not function in CCR in cells grown in LB medium [34]. However, the present northern blotting analyses of pts $G$ revealed a $4.6-\mathrm{kb}$ transcript in TM023 (ссрA::neo), 1A95 (degU32), and in TM024 (degU32 cсpA::neo) cells, but not in 168 or TM015 (degU32::cat) cells (Figure 8A). This 4.6-kb transcript is of sufficient size to cover the entire operon, and appeared in a similar manner to the 3.7-kb transcript containing rocG.

The lic operon encodes another PTS sugar transport system for the polysaccharide lichenan [35]. A 2.0-kb transcript containing lic C appeared in both 168 and $1 \mathrm{~A} 95$ cells, whereas another $4.0-\mathrm{kb}$ transcript was present in the strains carrying $\operatorname{deg} U 32$ or ccpA::neo, and then disappeared upon inactivation of $\operatorname{degU} 32$ (Figure $8 \mathrm{~B}$ ). This $2.0-\mathrm{kb}$ transcript may correspond with $\operatorname{lic} B C A$, and the $4.0-\mathrm{kb}$ transcript may reflect 


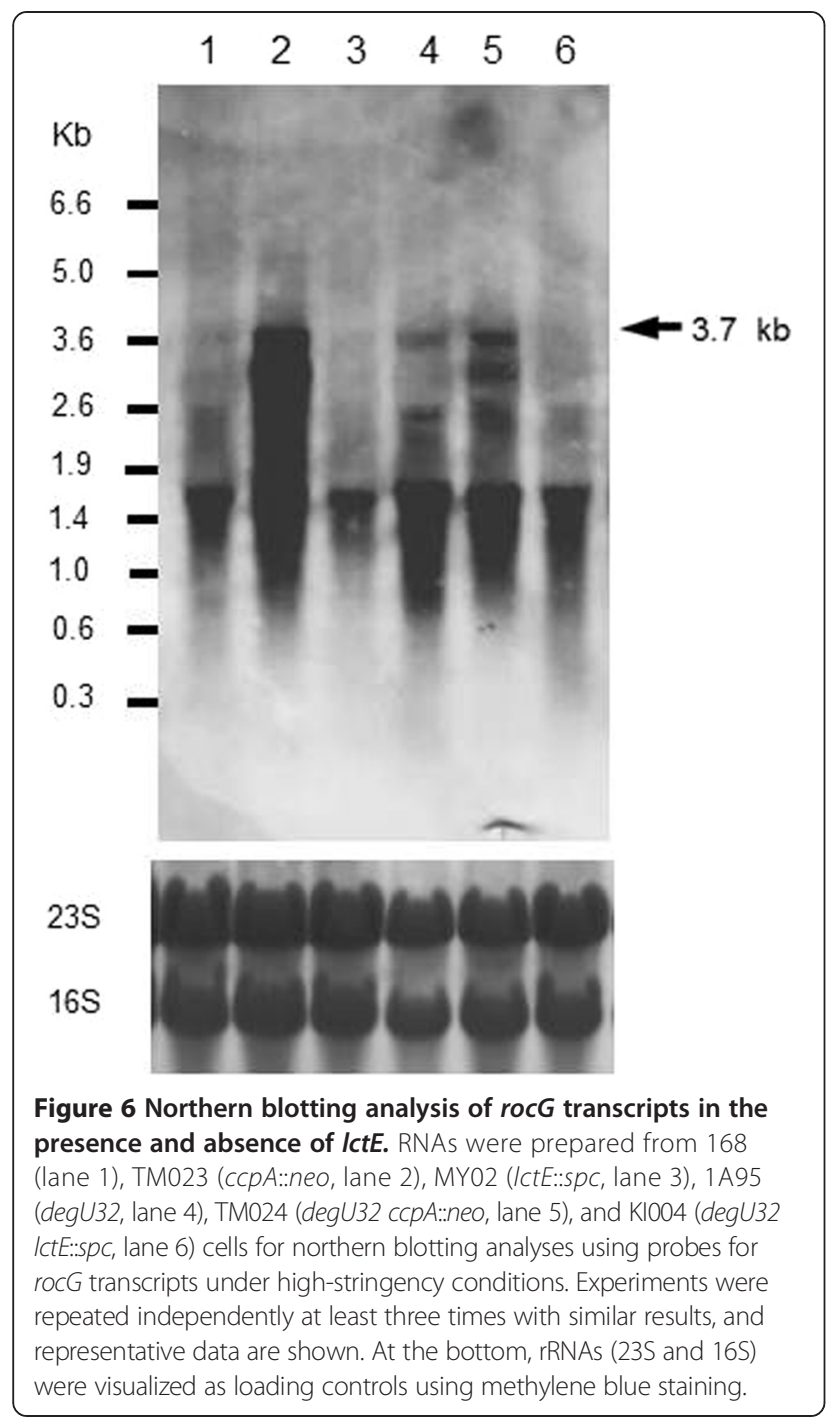

licRBCA. Moreover, a cre site in the intergenic region between licR and licB [35] may be involved in CcpAdependent CCR in 168 cells.

The dra-nupC-pdp operon is required for catabolism of deoxyribonucleoside [36], and although its transcription in 168 cells is strongly inhibited by glucose, it can be restored by introducing point mutations in the cre site within the reading frame of dra [37]. As shown in Figure $8 \mathrm{C}$, both $3.4-$ and 4.3-kb transcripts containing

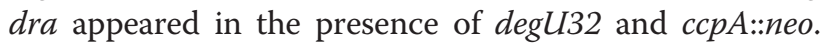
A smaller $0.6-\mathrm{kb}$ transcript might correspond to the monocistronic dra transcript, which was also dependent on $\operatorname{deg} U 32$ but not on $c c p A:: n e o$ by unknown reason.

Taken together, the present northern blotting analyses of ptsGHI, licRBCA, and deoR-dra-nupC-pdp operons suggest that $\operatorname{deg} U 32$ affects $\operatorname{roc} G$ and other CcpAdependent CCR targets.

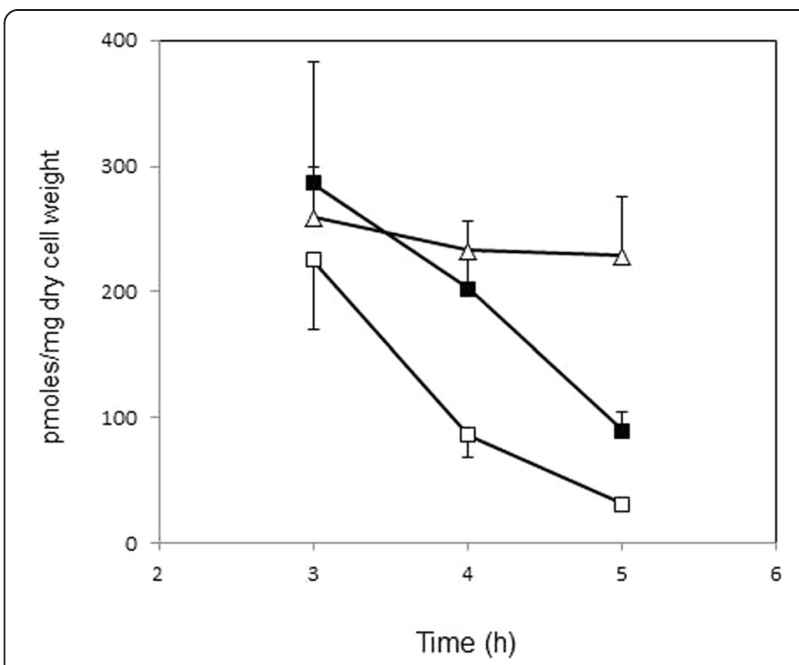

Figure 7 Intracellular levels of FBP in the presence and absence of IctE. Cells of 168 (closed squares), 1 A95 (degU32, open squares), and KI004 (degU32 ICtE::SpC, open triangles) cells were grown in the soytone-glucose medium, and intracellular metabolites were extracted at the indicated time points and were analyzed using CE-MS. Experiments were repeated independently for three times, and the mean values are shown with standard deviation.

\section{Discussion}

Numerous studies of CCR have been performed using the B. subtilis strain 168 as a model of gram-positive bacteria, and the mechanisms of CcpA-dependent CCR reportedly involve formation of a regulatory cre-site-binding complex by CcpA and P-Ser-HPr. CcpA-dependent CCR occurs naturally in 168 cells grown in the soytone-glucose medium containing $2 \%$ glucose. In contrast, DegU-P accumulated in 1A95 cells due to the degU32 mutation, and the presence of a novel $3.7-\mathrm{kb}$ transcript containing rocG suggested that CcpA-dependent CCR was proactively abolished.

Most of the described genes that are regulated by the DegS-DegU system are related to flagella formation, secretion of degradative enzymes such as protease and amylase, and biofilm formation [38,39]. Although few studies reported that DegS-DegU regulated genes for intracellular metabolic enzymes, depletion of nitrogen sources reportedly increased transcription of $\operatorname{deg} U$ through an interaction between TnrA and GlnA, which affected metabolism of nitrogen sources [40].

In the present study, the $\operatorname{deg} U 32$ mutation led to accumulation of DegU-P and elevated expression of $l c t E$, which encodes a lactate dehydrogenase that may enhance lactic acid synthesis in B. subtilis. Under anaerobic conditions, growing cells produce ATP and consume glycolytic intermediates by alternative respiration using the electron acceptor nitrate instead of oxygen or by fermentation to produce acetone, lactic acid, and acetolactate 


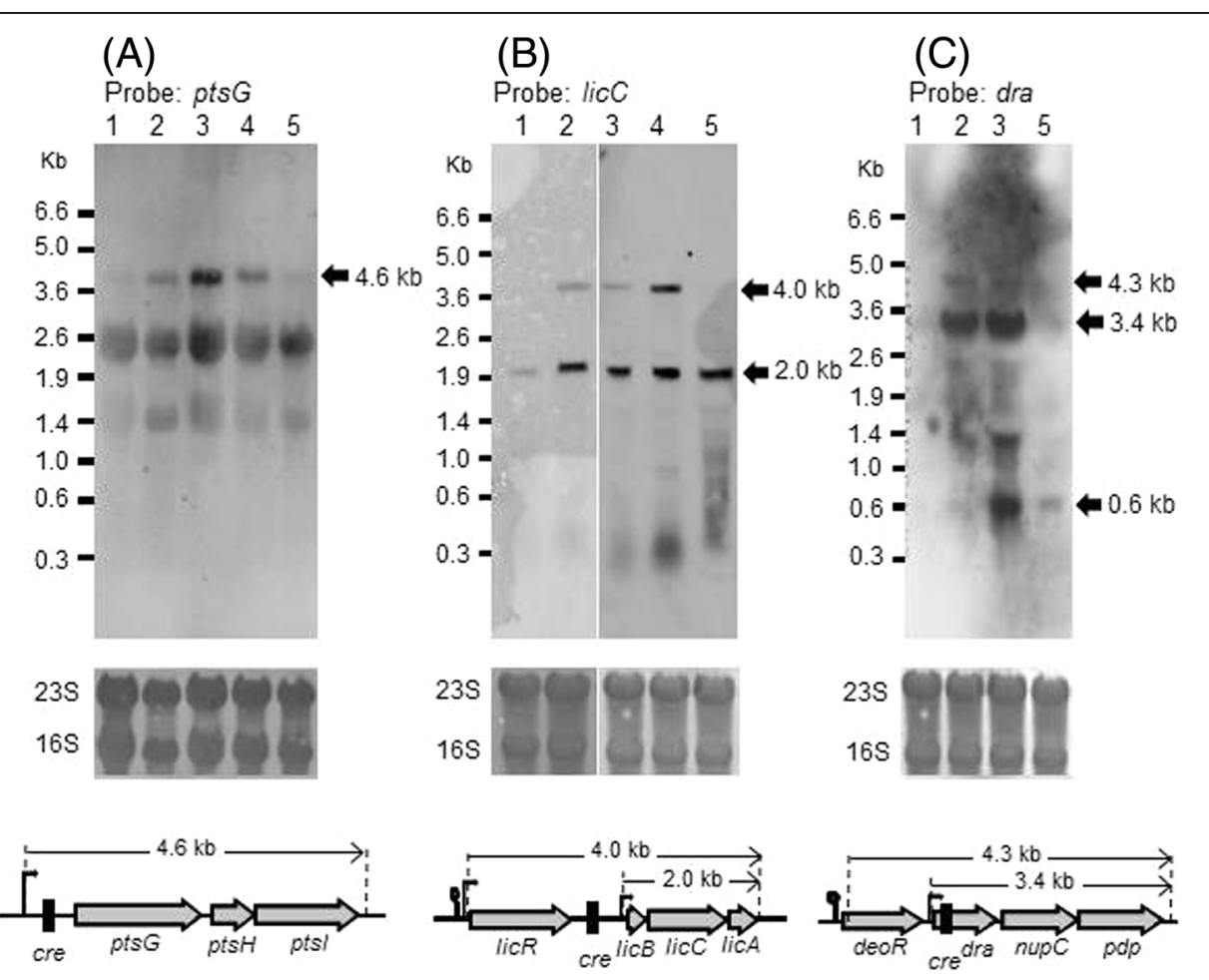

Figure 8 Northern blotting analyses of transcripts containing ptsG, licC, and dra. RNAs were prepared from 168 (lane 1), TM023 (ccpA::neo, lane 2), 1A95 (degU32, lane 3), TM024 (degU32 ccpA:neo, lane 4), and TM015 (degU32::cat, lane 5) cells for northern blotting analyses using probes for pts $G$ (A), licC (B), and dra (C) transcripts under higher-stringency conditions. Experiments were repeated independently at least three times with similar results and representative data are shown; rRNAs (23S and 16S) are shown on the membranes as loading controls. Genetic schemas of respective loci are shown below.

[41]. However, under the present aerobic conditions, cells did not need to produce lactic acid for energy production. Therefore, the counter-intuitive increase in lactic acid synthesis may promote clearance of glycolytic intermediates, including FBP, and may reflect inactivation of HPrK, reduced CcpA/P-Ser-HPr activity, and CCR blockade. Schilling and colleagues [42] compared intracellular metabolites of aerobically cultured $B$. subtilis in glucose minimal medium with and without succinic acid and glutamic acid supplementation. The supplementation strongly lowered oxaloacetate synthesis but increased lactic acid synthesis significantly. Thus, the presence of organic acid in addition to glucose may induce $l c t E$ transcription and expression of lactate dehydrogenase, which plays an important role in the control of the intracellular redox state.

Transcriptional control of $l c t E$ has predominantly been examined under anaerobic conditions, and another twocomponent system involving ResD-ResE [43], the intracellular $\mathrm{NAD}^{+}$and NADH redox sensor Rex [44], the two ECF sigma factors SigW and SigV [45], and a global regulator CodY [46] have been identified to be involved. The ResD-ResE system functions in global regulation of aerobic and anaerobic respiration and activates $\operatorname{res} A$, $c t a A, q c r A B C$, and fur $[47,48]$. Transcription of $l c t E$ is controlled directly by Fnr, which is an integral part of the regulatory cascade required for adaptation of bacteria to low oxygen tension [49]. B. subtilis Fnr differs structurally from that in other bacteria such as E. coli, and its unique functions have not been fully characterized [50]. Nonetheless, mutations in the two Fnr-binding sites within the $l c t E$ promoter region disabled induction of the promoter activity [41], indicating that $l c t E$ may be regulated by the ResD-ResE system through Fnr. DegU$\mathrm{P}$ recognizes and binds DNA carrying the relatively poorly conserved sequence motif AGAA-N11-TTCAG, and corresponding sequences are found within the promoter regions of a number of genes that are regulated by $\operatorname{deg} U$, including $w a p A, \operatorname{sac} B, \operatorname{sac} X Y, \operatorname{aprE}, \operatorname{deg} R, \operatorname{deg} Q$, $\operatorname{srf} A B, \operatorname{com} C, \operatorname{com} G, \operatorname{com} E A$, and mecA [16,51,52]. In contrast, non-phosphorylated DegU reportedly binds DNA with inverted repeat sequences with the consensus ATTTA-N7-TAAAT [53], which is similar to sequences in the promoter regions of $f n r$ and $l c t E$ (data not shown). However, further studies are required to determine whether $l c t E$ is regulated by non-phosphorylated $\operatorname{deg} U$. Moreover, at present we are unable to explain the mechanism how $l c t E$ was induced upon hyperphosphorylation of DegU.

Our transcriptome analyses revealed that ack $A$ and gnt $Z$ were induced for 5.86-, and 4.53-fold in 1A95 cells, 
respectively. Especially, the induction of ackA seemed contradictory, because ack $A$ is under positive regulation of CcpA/P-Ser-HPr and CcpA/P-Ser-Crh [31] and thus could be down regulated as FBP levels get lower. However, it is also known that ackA is induced by CodY in the presence of branched-chain amino acids [46]. 1A95 secretes extracellular proteases efficiently [14], and they could degrade soybean peptides in soytone-glucose medium to provide more branched-chain amino acids, which thus might trigger the CodY-dependent induction. On the other hand, gntZ is the last gene of the gntRKPZ operon for gluconate catabolism [27], which is under the control of two promoters; the one is the gnt promoter induced specifically in the presence of inducer gluconate and repressed with glucose via CcpA-dependent CCR [28], and the other just upstream of $g n t Z$ allowing its independent transcription [27]. Probably because of the absence of gluconate, the other gnt genes were scarcely transcribed, indicating that the gnt promoter was not active. Therefore, the latter promoter might be involved in the induction but is known not under CCR [27]. It might be worthwhile to investigate its specific induction upon hyperphosphorylation of DegU.

On the genetic background of the laboratory strain 168, degU32 caused accumulation of DegU-P and production of a novel $3.7-\mathrm{kb}$ transcript containing $\operatorname{roc} G$, suggesting that CcpA-dependent CCR was proactively abolished. In our preliminary experiments in the natto starter strain NAFM5, similar phenomena occurred as in 1A95 (the results would be described elsewhere). In 168 cells, $\operatorname{deg} Q$ is not efficiently transcribed due to a mutation in its cognate promoter [10]. Thus, DegU-P levels remain lower in these cells, whereas in wild-type strains such as natto starter strains, DegQ may enhance DegU phosphorylation instead of $\operatorname{deg} U 32$ transcription. Potential to abort CCR with hyperphosphorylation of DegU may have offered survival advantageous in many other bacteria that utilize various carbon sources in environmental competition, but could have been lost during domestication to breed the laboratory strain 168. The DegS-DegU system interacts with the ComP-ComA two-component system that is involved in natural competence. Upon increases in cell density, ComA is phosphorylated and activates DegQ [7], suggesting a shared function of DegQ in the ComP-ComA and DegS-DegU systems. However, unphosphorylated DegU is essential for the expression of the competence transcription factor encoded by $\operatorname{comK}$ [4]; and thus, hyperphosphorylation of DegU may restrict natural competence as unphosphorylated DegU decreased. Because strain 168 was selected for its high natural competence, the $\operatorname{deg} Q$ promoter may have been mutated to avoid accumulation of DegU-P enhanced by DegQ following activation of the ComP-ComA system.
The present northern blotting analyses of the $\operatorname{roc} G$ locus suggested constitutive transcription from the $\operatorname{siv} A$ promoter (Figure 2B). However, this transcription is not completely terminated at the Rho-independent terminator (Figure $3 \mathrm{C}$ ) and is usually aborted at the downstream cre site via the CcpA-dependent CCR roadblock mechanism [17]. Thus, upon alleviation of CCR, rocG may be induced immediately, leading to formation of the $3.7-\mathrm{kb}$ transcript shown in 1A95 cells, which may represent a novel mode of CcpA-dependent regulation to induce the target gene. In this study, it was implied that hyperphosphorylation of DegU induced lctE through unknown mechanisms to decrease intracellular FBP levels earlier and thus proactively cancelled the CCR roadblock. Potentially, this mode of regulation may operate at the global level, as suggested by transcriptome (Table 1) as well as the other northern blotting analyses (Figure 8). The physiological significance of this mechanism requires further investigation.

\section{Conclusions}

The 3.7-kb transcript covering $\operatorname{siv} A$, rocG, and rocA may be tightly controlled under physiological conditions by a roadblock mechanism involving $\mathrm{P}-\mathrm{Ser}-\mathrm{HPr} / \mathrm{CcpA}$ in 168 cells, while in 1A95 cells the tight control was alleviated. Accumulation of DegU-P in 1A95 cells affects central carbon metabolism involving $l c t E$ enhanced by unknown mechanisms, downregulates FBP levels earlier, and inactivates HPrK to allow the 3.7-kb transcription. Similar events may occur in other catabolite repressive loci.

\section{Methods}

\section{Bacterial strains and media}

The bacterial strains and plasmids used in this study are listed in Table 2. Strains of B. subtilis were routinely maintained on TBABG plate medium containing 3.3\% tryptose blood agar base (Becton, Dickinson and Company, NJ, USA) and $0.18 \%$ glucose. To induce experimental growth, cells were precultured on TBABG plates for $16 \mathrm{~h}$ at $37^{\circ} \mathrm{C}$, and fresh colonies were then inoculated into $30-40 \mathrm{ml}$ of soytone-glucose medium containing 1.0\% Bacto-soytone (Becton, Dickinson and Company), 0.5\% Bacto yeast extract (Becton, Dickinson and Company), $1.0 \% \mathrm{NaCl}$, and $2.0 \%$ glucose (pH 7.0) in a $500-\mathrm{ml}$ shaking flask at $\mathrm{OD}_{600}$ of 0.05 , and were grown at $37^{\circ} \mathrm{C}$ with shaking at $150 \mathrm{rpm}$. The Escherichia coli strain was grown in LB medium. When required, cells were cultured in the presence of $100 \mu \mathrm{g} / \mathrm{ml}$ ampicillin, $0.5 \mu \mathrm{g} / \mathrm{ml}$ erythromycin, $50 \mu \mathrm{g} / \mathrm{ml}$ kanamycin, $10 \mu \mathrm{g} / \mathrm{ml}$ chloramphenicol, $100 \mu \mathrm{g} / \mathrm{ml}$ spectinomycin, or $15 \mu \mathrm{g} / \mathrm{ml}$ neomycin.

\section{Construction of strains}

The strains TM013 and TM014 were constructed from respective parental strains 168 and 1A95 by transformation 
Table 2 List of bacterial strains

\begin{tabular}{|c|c|c|}
\hline Strain & Genotype & $\begin{array}{l}\text { Source or } \\
\text { reference }\end{array}$ \\
\hline \multicolumn{3}{|l|}{ B. subtilis } \\
\hline 168 & $\operatorname{trpC2}$ & Laboratory stock \\
\hline 1A95 & $\operatorname{trp} C 2 \operatorname{deg} \cup 32$ & {$[14]$} \\
\hline WTF28 & $\operatorname{deg} U:: c a t$ & {$[8]$. } \\
\hline BFS3227 & $\operatorname{trpC2}$ sivA::pMutin2 & NIG, Japan \\
\hline$\Delta \operatorname{rocR}(\mathrm{FW} 15)$ & pheA1 sfp0 trpC2 rocR::kan & {$[55]$} \\
\hline FU402 & $\operatorname{trp} C 2$ cсpA::neo & {$[57]$} \\
\hline TM013 & $\operatorname{trpC2}$ rocG::cat & This study \\
\hline TM014 & $\operatorname{trpC2}$ degU32 rocG::cat & This study \\
\hline TM015 & $\operatorname{trp} C 2$ degU32::cat & This study \\
\hline TM016 & $\operatorname{trp} C 2$ degU32 rocR::kan & This study \\
\hline TM017 & $\operatorname{trpC2}$ sivA::.pMutin2 & This study \\
\hline TM018 & $\operatorname{trpC2} \operatorname{deg} U 32$ sivA::pMutin2 & This study \\
\hline TM023 & $\operatorname{trp} C 2$ cсpA::neo & This study \\
\hline TM024 & $\operatorname{trp} C 2 \operatorname{deg} U 32$ cсpA::neo & This study \\
\hline MY02 & $\operatorname{trp} C 2$ lctE::spc & This study \\
\hline $\mathrm{KI} 004$ & $\operatorname{trpC2}$ degU32 IctE::spc & This study \\
\hline \multicolumn{3}{|l|}{ E. coli } \\
\hline $\mathrm{DH} 5 \mathrm{a}$ & $\begin{array}{l}\text { supE44 } \triangle \text { lacU169 hsdR17 recA1 endA1 } \\
\text { gyrA1 gyrA96 thi-1 relA1 }\end{array}$ & Laboratory stock \\
\hline \multicolumn{3}{|l|}{ Plasmid } \\
\hline pGP958 & rocG::cat & {$[54]$} \\
\hline
\end{tabular}

with pGP958 plasmid DNA [54] harboring a chloramphenicol resistance gene cassette inactivating rocG. To construct TM015, 1A95 cells were transformed with chromosomal DNA from WTF28 [8] carrying a chloramphenicol resistance gene cassette inactivating $\operatorname{deg} U 32$. To construct TM016, 1A95 cells were transformed with DNA from the strain $\Delta$ rocR (FW15) [55], which harbored a kanamycin resistance gene cassette inactivating rocR. TM017 and TM018 strains were constructed by transformation of 168 and 1A95 cells with DNA from the strain BFS3227 (National BioResource Project; NIG, Japan; $B$. subtilis), which harbored an erythromycin resistance gene cassette inactivating $\operatorname{siv} A$ (formerly yweA) [56]. TM023 and TM024 strains were constructed by transformation of 168 and 1A95 cells with DNA from the strain FU402 [57], which harbored a neomycin resistance gene cassette inactivating $c c p A$.

MY02 and KI004 were constructed as follows: two DNA fragments (approximately 500-bp long) corresponding to the flanking regions upstream and downstream of $l c t E$ (also called $l d h$ ) were amplified using chromosomal DNA from 168 cells as a PCR template and the respective primers lctE-R2/lctE-R1 and lctE-F2/lctE-F1 (Table 3). Another PCR fragment containing the spectinomycin resistance gene cassette was amplified using DNA from the
Table 3 List of oligonucleotide primers

\begin{tabular}{ll}
\hline Name & Sequence $\mathbf{( 5}^{\prime}$ to $\mathbf{3}^{\prime}$ ) \\
\hline IctE-F1 & ttggagccaggtaatgctt \\
IctE-R1 & acaaaacccgctccgatta \\
IctE-spec-F & taatcggagcgggttttgtcaataacgctattgggag \\
IctE-spec-R & cagctcagtgatacctgcgactatatgctccttctggc \\
IctE-F2 & tcgcaggtatcactgagctg \\
IctE-R2 & gcaatgctggaccgaataat \\
NrocG-F & atattccagctcccgatgtg \\
NrocG-R-T7 & taatacgactcactatagggtggtgaccataccaaagctg \\
NptsG-F & catcaatcgaggcaaaaaca \\
NptsG-R-T7 & taatacgactcactatagggatcaccagctgcgtttcag \\
NlicC-F & gcagcaaaatttgtcgaggt \\
NlicC-R-T7 & taatacgactcactataggggacagtcagcgtttggtca \\
Ndra-F & cagctttgaaaccgcataca \\
Ndra-R-T7 & taatacgactcactatagggcggcctctaccattgtgtct \\
NlctE-F & ccggtcaaaacatcttacgg \\
NlctE-R-T7 & taatacgactcactatagggagttcactgaccggcacac \\
PEyweA-F & aacaggaaggaattctcattgaa \\
PEyweA-R & atggtccactctttcgtgct \\
\hline
\end{tabular}

strain FU341 [58] and the primers lctE-spec-R and lctEspec-F (Table 3). A mixture of the three DNA fragments was used as a template for PCR, and the primer pair lctER2/lctE-F1 was used to generate a recombinant fragment of the spectinomycin resistance gene sandwiched between the flanking regions upstream and downstream of $l c t E$. This recombinant fragment was used to transform 168 and 1A95 cells with the spectinomycin resistance gene and inactivated $l c t E$ to obtain MY02 and KI004 strains, respectively.

\section{RNA analysis}

RNA samples were prepared as previously described [59] with some modifications. Briefly, cells were grown to the transition state from logarithmic and stationary phases (4 h after inoculation). Subsequently, 20-ml aliquots of the culture were centrifuged, and cell pellets were resuspended in $1 \mathrm{ml}$ of LETS buffer containing 1\% SDS, $100 \mathrm{mM} \mathrm{LiCl}, 10 \mathrm{mM}$ EDTA, and $10 \mathrm{mM}$ Tris- $\mathrm{HCl}$ $(\mathrm{pH}$ 7.4). After addition of $500 \mu \mathrm{l}$ of glass beads $(\phi 0.5 \mathrm{~mm})$ and $1 \mathrm{ml}$ of phenol:chloroform:isoamyl alcohol (25:24:1), cells were disrupted with vigorous shaking and were then centrifuged. Finally, purified RNA was precipitated from the upper aqueous phase using ethanol.

Northern blotting and primer extension analyses were performed as described previously [60]. Briefly, probes for northern blotting analyses were prepared using in vitro transcription with T7 RNA polymerase from template DNAs of PCR fragments that were generated 
using the following respective primer pairs (Table 2): rocG, NrocG-F/NrocG-R-T7; sivA, NyweA-F/NyweA-R-T7; $\operatorname{rocA}, \quad$ NrocA-F/NrocA-R-T7; ltcE, NlctE-F/NlctE-R-T7; ptsG, NptsG-F/NptsG-R-T7; licC, NlicC-F/NlicC-R-T7; and dra, Ndra-F/Ndra-R-T7. Hybridization was performed for $16 \mathrm{~h}$ at $50^{\circ} \mathrm{C}$ (lower stringency) or $55^{\circ} \mathrm{C}$ (higher stringency). In primer extension experiments for the sivA promoter region, RNA samples were subjected to reverse transcription using the specific primer PEyweA-R (Table 2), which was $5^{\prime}$-end labelled with $\left[\gamma^{-}{ }^{32} \mathrm{P}\right]$ ATP (GE Healthcare BioSciences, NJ, USA) using a MEGALABEL kit (Takara Bio Inc., Otsu, Japan). Sequence ladders were produced from the same primer using dideoxy sequencing reactions, and the template PCR fragment was amplified from the 168 strain using the primers PEyweA-F and PEyweA-R (Table 3).

Transcriptome analyses were performed using a highdensity tiling oligonucleotide chip as described previously [61]. Briefly, cDNAs were synthesized from RNAs and were labelled and hybridized to the oligonucleotide chip using established methods [62]. To compensate for differences in hybridization efficiency of 25-mer oligonucleotide probes on the chip, hybridization intensities of cDNAs were divided with that of total genome DNA. Normalized transcriptional signals were processed and analyzed using the In Silico Molecular Cloning program, Array Edition (In Silico Biology, Yokohama, Japan). The data are available in the ArrayExpress database [63] under accession number E-MTAB-2944.

\section{Measurement of metabolites}

Metabolic intermediates of central carbon metabolism were determined in 168 and 1A95 cells grown on the soytoneglucose medium. At the indicated time points, 10-ml aliquots of bacterial cultures were quickly mixed into $14 \mathrm{ml}$ of methanol at $-40^{\circ} \mathrm{C}$, and the mixture was then incubated for a further $15 \mathrm{~min}$ at $-40^{\circ} \mathrm{C}$. After centrifugation at $7,000 \mathrm{rpm}$ for 5 minutes at $-20^{\circ} \mathrm{C}$, the supernatant was discarded and $7.5 \mu \mathrm{l}$ of $100 \mathrm{mM}$ adipic acid and $7.5 \mu \mathrm{l}$ of $1 \mathrm{mM}$ 1,4-piperazinediethanesulfonic acid were added to the remaining cell pellets as internal standards. To extract metabolites, cell pellets were disrupted with vigorous mixing in $1 \mathrm{ml}$ of $75 \%(\mathrm{v} / \mathrm{v})$ ethanol that was preheated to $95^{\circ}$ C. Extracts were then evaporated under vacuum and subjected to the CE-MS analysis performed as previously described [64]. Ammonia contents of culture media were measured using an ammonia assay kit (Sigma-Aldrich, MO, USA) according to the supplier's instructions.

\section{Additional file 1}

Additional file 1: Figure S1. Northern blotting analyses of transcripts containing rocB RNAs were prepared from 168 (lane 1), 1 A95 (degU32, lane 2), TM015 (degU32::cat, lane 3), TM016 (degU32 rocR::kan, lane 4), and
TM024 (degU32 ccpA::neo, lane 5) cells. The rocB-specific probe was prepared using in vitro transcription with T7 RNA polymerase from the template DNA of PCR fragment that was generated using the primer pairs of NrocB-F (5'-aatcaggcgagtggatgttc-3') and NrocB-R-T7 (5'-taatacga ctcactatagggtattgtggagacggcttgtg-3'). rRNAs (23S and 16S) on membrane were visualized as a loading control using methylene blue staining.

\section{Competing interests}

The authors declare that the research was conducted in the absence of any commercial or financial relationships that could be construed as a potential conflict of interest.

\section{Authors' contributions}

$\mathrm{KT}, \mathrm{Kl}, \mathrm{TMO}, \mathrm{TMa}, \mathrm{OC}$, and $\mathrm{SI}$ carried out the molecular genetic studies including the transcriptome and CE-MS analyses, and participated in drafting the manuscript. TH supervised the CE-MS analysis. ST, NO, and KY coordinated the collaboration. KY conceived of the study, conducted it, and prepared the final manuscript. All authors read and approved the final manuscript.

\section{Acknowledgements}

The plasmid pGP958 was provided by J. Stülke. The strains $\Delta$ rocR (FW15), WTF28, FU402, and BFS3227 were kind gifts from M. Débarbouillé, K. Kobayashi, Y. Miwa, and National BioResource Project (NIG, Japan), respectively. We thank $\mathrm{S}$. Kada for measuring ammonia levels in culture media. This work was financially supported by the Ministry of Education, Culture, Sports, Science and Technology, Japan; in parts by Special Coordination Funds for Promoting Science and Technology, Creation of Innovative Centers for Advanced Interdisciplinary Research Areas, by the Advanced Low-Carbon Technology Research and Development Program, by KAKENHI (26660067), and by Grants-in-Aid from the NC-CARP project.

\section{Author details}

'Organization of Advanced Science and Technology, Kobe University, Kobe, Hyogo, Japan. ${ }^{2}$ Department of Agrobioscience, Kobe University, Kobe, Hyogo, Japan. ${ }^{3}$ Biological Science Laboratories, Kao Corporation, Haga, Tochigi, Japan. ${ }^{4}$ Graduate School of Biological Sciences, Nara Institute of Science and Technology, Ikoma, Nara, Japan.

Received: 19 January 2015 Accepted: 4 February 2015

Published online: 22 February 2015

\section{References}

1. Stock AM, Robinson VL, Goudreau PN. Two-component signal transduction. Annu Rev Biochem. 2000;69:183-215. doi:10.1146/annurev.biochem.69.1.183.

2. Msadek T, Kunst F, Henner D, Klier A, Rapoport G, Dedonder R. Signal transduction pathway controlling synthesis of a class of degradative enzymes in Bacillus subtilis: expression of the regulatory genes and analysis of mutations in degS and degU. J Bacteriol. 1990;172:824-34.

3. Ogura M, Tanaka T. Bacillus subtilis DegU acts as positive regulator for comK expression. FEBS Lett. 1996;397:173-6. doi:10.1016/S0014-5793(96)01170-2.

4. Hamoen LW, van Werkhoven AF, Venema G, Dubnau D. The pleiotropic response regulator DegU functions as a priming protein in competence development in Bacillus subtilis. Proc Natl Acad Sci U S A. 2000;97:9246-51. doi:10.1073/pnas.160010597.

5. Márquez LM, Helmann JD, Ferrari E, Parker HM, Ordal GW, Chamberlin MJ. Studies of sigma D-dependent functions in Bacillus subtilis. J Bacteriol. 1990;172:3435-43.

6. Tokunaga T, Rashid MH, Kuroda A, Sekiguchi J. Effect of degS-degU mutations on the expression of sigD, encoding an alternative sigma factor, and autolysin operon of Bacillus subtilis. J Bacteriol. 1994;176:5177-80.

7. Msadek T, Kunst F, Klier A, Rapoport G. DegS-DegU and ComP-ComA modulator-effector pairs control expression of the Bacillus subtilis pleiotropic regulatory gene degQ. J Bacteriol. 1991;173:2366-77.

8. Kobayashi K. Gradual activation of the response regulator DegU controls serial expression of genes for flagellum formation and biofilm formation in Bacillus subtilis. Mol Microbiol. 2007;66:395-409. doi:10.1111/j.1365-2958.2007.05923.x.

9. Mukai K, Kawata-Mukai M, Tanaka T. Stabilization of phosphorylated Bacillus subtilis DegU by DegR. J Bacteriol. 1992;174:7954-62. 
10. Stanley NR, Lazazzera BA. Defining the genetic differences between wild and domestic strains of Bacillus subtilis that affect poly-gamma-dl-glutamic acid production and biofilm formation. Mol Microbiol. 2005;57:1143-58. doi:10.1111/j.1365-2958.2005.04746.x.

11. Kunst F, Pascal M, Lepesant-Kejzlarova J, Lepesant JA, Billault A, Dedonder R. Pleiotropic mutations affecting sporulation conditions and the syntheses of extracellular enzymes in Bacillus subtilis 168. Biochimie. 1974;56:1481-9.

12. Dahl MK, Msadek T, Kunst F, Rapoport G. Mutational analysis of the Bacillus subtilis DegU regulator and its phosphorylation by the DegS protein kinase. J Bacteriol. 1991;173:2539-47.

13. Dahl KM, Msadek T, Kunst F, Rapoport G. The phosphorylation state of the DegU response regulator acts as a molecular switch allowing either degradative enzyme synthesis or expression of genetic competence in Bacillus subtilis. J Biol Chem. 1992;267:14509-14.

14. Henner DJ, Ferrari E, Perego M, Hoch JA. Location of the targets of the hpr-97, sacU32 (Hy), and sacQ36 (Hy) mutations in upstream regions of the subtilisin promoter. J Bacteriol. 1988;170:296-300.

15. Antelmann H, Tjalsma H, Voigt B, Ohlmeier S, Bron S, van Dijl JM, et al. A proteomic view on genome-based signal peptide predictions. Genome Res. 2001;11:1484-502. doi:10.1101/gr.182801.

16. Mäder U, Antelmann H, Buder T, Dahl MK, Hecker M, Homuth G. Bacillus subtilis functional genomics: genome-wide analysis of the DegS-DegU regulon by transcriptomics and proteomics. Mol Genet Genomics. 2002;268:455-67.

17. Fujita Y. Carbon catabolite control of the metabolic network in Bacillus subtilis. Biosci Biotechnol Biochem. 2009;732:45-59. doi:10.1271/bbb.80479.

18. Kada S, Yabusaki M, Kaga T, Ashida H, Yoshida K. Identification of two major ammonia-releasing reactions involved in secondary natto fermentation. Biosci Biotechnol Biochem. 2008;72:1869-76. doi:10.1271/bbb.80129.

19. Gardan R, Rapoport G, Débarbouillé M. Role of the transcriptional activator RocR in the arginine-degradation pathway of Bacillus subtilis. Mol Microbiol. 1997;24:825-37. doi:10.1046/j.1365-2958.1997.3881754.x.

20. Belitsky BR, Sonenshein AL. An enhancer element located downstream of the major glutamate dehydrogenase gene of Bacillus subtilis. Proc Natl Acad Sci U S A. 1999;96:10290-95. doi:10.1073/pnas.96.18.10290.

21. Ali NO, Jeusette J, Larquet E, Cam EL, Belitsky B, Sonenshein AL, et al. Specificity of the interaction of RocR with the rocG-rocA intergenic region in Bacillus subtilis. Microbiology. 2003;149:739-50. doi:10.1099/mic. 0.26013-0.

22. Belitsky BR, Kim HJ, Sonenshein AL. CcpA-dependent regulation of Bacillus subtilis glutamate dehydorogenase gene expression. J Bacteriol. 2004;186:3392-8. doi:10.1128/JB.186.11.3392-3398.2004.

23. Calogero S, Gardan R, Glaser P, Schweizer J, Rapoport G, Debarbouille M. RocR, a novel regulatory protein controlling arginine utilization in Bacillus subtilis, belongs to the NtrC/NifA family of transcriptional activators. J Bacteriol. 1994;176:1234-41.

24. Nicolas P, Mäder U, Dervyn E, Rochat T, Leduc A, Pigeonneau N, et al. Condition-dependent transcriptome reveals high-level regulatory architecture in Bacillus subtilis. Science. 2012;335:1103-6. doi:10.1126/ science.1206848.

25. B. subtilis Expression Data Browser. INRA-MIG. Gene/Segment: rocA Locus Tag: BSU37780. http://genome.jouy.inra.fr/cgi-bin/seb/viewdetail.py? id=rocA_3878966_3880513_-1. Accessed 16 Jan 2015.

26. Choi SK, Saier Jr MH. Regulation of sigL expression by the catabolite control protein CcpA involves a roadblock mechanism in Bacillus subtilis: potential connection between carbon and nitrogen metabolism. J Bacteriol. 2005;187:6856-61. doi:10.1128/JB.187.19.6856-6861.2005.

27. Fujita Y, Fujita T, Miwa Y, Nihashi J, Aratani Y. Organization and transcription of the gluconate operon, gnt, of Bacillus subtilis. J Biol Chem. 1986:261:13744-53.

28. Miwa Y, Nagura K, Eguchi S, Fukuda H, Deutscher J, Fujita Y. Catabolite repression of the Bacillus subtilis gnt operon exerted by two catabolite-responsive elements. Mol Microbiol. 1997;23:1203-13. doi:10.1046/j.1365-2958.1997.2921662.x.

29. Grundy FJ, Waters DA, Allen SH, Henkin TM. Regulation of the Bacillus subtilis acetate kinase gene by CcpA. J Bacteriol. 1993;175:7348-55.

30. Presecan-Siedel E, Galinier A, Longin R, Deutscher J, Danchin A, Glaser P, et al. Catabolite regulation of the pta gene as part of carbon flow pathways in Bacillus subtilis. J Bacteriol. 1999;181:6889-97.

31. Turinsky AJ, Grundy FJ, Kim JH, Chambliss GH, Henkin TM. Transcriptional activation of the Bacillus subtilis ackA gene requires sequences upstream of the promoter. J Bacteriol. 1998;180:5961-7.
32. Marciniak BC, Pabijaniak $M$, de Jong A, Dühring $R$, Seidel $G$, Hillen $W$, et al. High- and low-affinity cre boxes for CcpA binding in Bacillus subtilis revealed by genome-wide analysis. BMC Genomics. 2012;13:401. doi:10.1186/1471-2164-13-401.

33. Stülke J, Martin-Verstraete I, Zagorec M, Rose M, Klier A, Rapoport G. Induction of the Bacillus subtilis ptsGHI operon by glucose is controlled by a novel antiterminator, GlcT. Mol Microbiol. 1997;25:65-78. doi:10.1046/j.1365-2958.1997.4351797.x.

34. Moreno MS, Schneider BL, Maile RR, Weyler W, Saier Jr MH. Catabolite repression mediated by the $\mathrm{CcPA}$ protein in Bacillus subtilis: novel modes of regulation revealed by whole-genome analyses. Mol Microbiol. 2001;39:1366-81. doi:10.1111/j.1365-2958.2001.02328.x.

35. Tobisch $S$, Glaser $P$, Krüger $S$, Hecker M. Identification and characterization of a new beta-glucoside utilization system in Bacillus subtilis. J Bacteriol. 1997;179:496-506.

36. Saxild HH, Andersen LN, Hammer K. dra-nupC-pdp operon of Bacillus subtilis: nucleotide sequence, induction by deoxyribonucleosides, and transcriptional regulation by the deoR-encoded DeoR repressor protein. J Bacteriol. 1996;178:424-34.

37. Zeng X, Galinier A, Saxild HH. Catabolite repression of dra-nupC-pdp operon expression in Bacillus subtilis. Microbiology. 2000;146:2901-8.

38. Verhamme DT, Kiley TB, Stanley-Wall NR. DegU co-ordinates multicellular behaviour exhibited by Bacillus subtilis. Mol Microbiol. 2007;65:554-68. doi:10.1111/j.1365-2958.2007.05810.x.

39. Amati G, Bisicchia P, Galizzi A. DegU-P represses expression of the motility fla-che operon in Bacillus subtilis. J Bacteriol. 2004;186:6003-14. doi:10.1128/JB.186.18.6003-6014.2004.

40. Yasumura A, Abe S, Tanaka T. Involvement of nitrogen regulation in Bacillus subtilis degU expression. J Bacteriol. 2008;190:5162-71. doi:10.1128/JB.00368-08.

41. Cruz Ramos H, Hoffmann T, Marino M, Nedjari H, Presecan-Siedel E, Dreesen $\mathrm{O}$, et al. Fermentative metabolism of Bacillus subtilis: physiology and regulation of gene expression. J Bacteriol. 2000;182:3072-80. doi:10.1128/JB.182.11.3072-3080.2000

42. Schilling O, Frick O, Herzberg C, Ehrenreich A, Heinzle E, Wittmann C, et al. Transcriptional and metabolic responses of Bacillus subtilis to the availability of organic acids: transcription regulation is important but not sufficient to account for metabolic adaptation. Appl Environ Microbiol. 2007;73:499-507. doi:10.1128/AEM. 02084-06

43. Marino M, Ramos HC, Hoffmann T, Glaser P, Jahn D. Modulation of anaerobic energy metabolism of Bacillus subtilis by arfM (ywiD). J Bacteriol. 2001;183:6815-21. doi:10.1128/JB.183.23.6815-6821.2001.

44. Larsson JT, Rogstam A, von Wachenfeldt C. Coordinated patterns of cytochrome bd and lactate dehydrogenase expression in Bacillus subtilis. Microbiology. 2005;151:3323-35. doi:10.1099/mic. 0.28124-0.

45. Asai K, Yamaguchi H, Kang CM, Yoshida, Fujita Y, Sadaie Y. DNA microarray analysis of Bacillus subtilis sigma factors of extracytoplasmic function family. FEMS Microbiol Lett. 2003;220:155-60. doi:10.1016/S0378-1097 (03) 00093-4.

46. Shivers RP, Dineen SS, Sonenshein AL. Positive regulation of Bacillus subtilis ackA by CodY and CcpA: establishing a potential hierarchy in carbon flow. Mol Microbiol. 2006;62:811-22. doi:10.1111/j.1365-2958.2006.05410.x.

47. Sun G, Sharkova E, Chesnut R, Birkey S, Duggan MF, Sorokin A, et al. Regulators of aerobic and anaerobic respiration in Bacillus subtilis. J Bacteriol. 1996;178:1374-85.

48. Nakano MN, Zuber P, Glaser P, Danchin A, Hulett FM. Two-component regulatory proteins ResD-ResE are required for transcriptional activation of fnr upon oxygen limitation in Bacillus subtilis. J Bacteriol. 1996;178:3796-802.

49. Reents $H$, Münch R, Dammeyer $T$, Jahn D, Härtig E. The Fnr regulon of Bacillus subtilis. J Bacteriol. 2006;188:1103-12. doi:10.1128/JB.188.3.11031112.2006.

50. Komori H, Seo D, Sakurai T, Higuchi Y. Crystal structure analysis of Bacillus subtilis ferredoxin-NADP ${ }^{+}$oxidoreductase and the structural basis for its substrate selectivity. Protein Sci. 2010;19:2279-90. doi:10.1002/pro.508.

51. Dartois V, Débarbouillé $M$, Kunst F, Rapoport G. Characterization of a novel member of the DegS-DegU region affected by salt stress in Bacillus subtilis. J Bacteriol. 1998;180:1855-61.

52. Ogura M, Yamaguchi H, Yoshida K, Fujita Y, Tanaka T. DNA microarray analysis of Bacillus subtilis DegU, ComA and PhoP regulons: an approach to comprehensive analysis of $B$. subtilis two-component regulatory systems. Nucleic Acids Res. 2001;29:3804-13. doi:10.1093/nar/29.18.3804. 
53. Ogura M, Tsukahara K. Autoregulation of the Bacillus subtilis response regulator gene deg $U$ is coupled with the proteolysis of DegU-P by ClpCP. Mol Microbiol. 2010;75:1244-59. doi:10.1111/j.1365-2958.2010.07047.x.

54. Commichau FM, Herzberg C, Tripal P, Valerius O, Stülke J. A regulatory protein-protein interaction governs glutamate biosynthesis in Bacillus subtilis: the glutamate dehydrogenase RocG moonlights in controlling the transcription factor GltC. Mol Microbiol. 2007;65:642-54. doi:10.1111/j.1365-2958.2007.05816.x.

55. Wiegeshoff F, Beckering CL, Debarbouille M, Marahiel MA. Sigma L is important for cold shock adaptation of Bacillus subtilis. J Bacteriol. 2006;188:3130-3. doi:10.1128/JB.188.8.3130-3133.2006

56. Garti-Levi S, Eswara A, Smith Y, Fujita M, Ben-Yehuda S. Novel modulators controlling entry into sporulation in Bacillus subtilis. J Bacteriol. 2013;195:1475-83. doi:10.1128/JB.02160-12.

57. Tojo S, Satomura T, Morisaki K, Deutscher J, Hirooka K, Fujita Y. Elaborate transcription regulation of the Bacillus subtilis ilv-leu operon involved in the biosynthesis of branched-chain amino acids through global regulators of CcpA, CodY and TnrA. Mol Microbiol. 2005;56:1560-73. doi:10.1111/j.1365-2958.2005.04635.x.

58. Yoshida K, Fujita Y, Ehrlich SD. Three asparagine synthetase genes of Bacillus subtilis. J Bacteriol. 1999;181:6081-91.

59. Igo MM, Losik R. Regulaton of a promoter that is utilized by minor forms of RNA polymerase holoenzyme in Bacillus subtilis. J Mol Biol. 1986;191:615-24. doi:10.1016/0022-2836 (86) 90449-3.

60. Yoshida K, Sanbongi A, Murakami A, Suzuki H, Takenaka S, Takami H. Three inositol dehydrogenases involved in utilization and interconversion of inositol stereoisomers in a thermophile, Geobacillus kaustophilus HTA426. Microbiology. 2012:158:1942-52. doi:10.1099/mic. 0.059980-0.

61. Ishikawa S, Ogura Y, Yoshimura M, Okumura H, Cho E, Kawai Y, et al. Distribution of stable DnaA-binding sites on the Bacillus subtilis genome detected using a modified ChIP-chip method. DNA Res. 2007;14:155-68. doi:10.1093/dnares/dsm017

62. Oshima T, Ishikawa S, Kurokawa K, Aiba H, Ogasawara N. Escherichia coli histone-like protein H-NS preferentially binds to horizontally acquired DNA in association with RNA polymerase. DNA Res. 2006;13:141-53. doi:10.1093/dnares/dsl009.

63. ArrayExpress database. EMBL-EBI. www.ebi.ac.uk/arrayexpress.

64. Hasunuma T, Sanda T, Yamada R, Yoshimura K, Ishii J, Kondo A. Metabolic pathway engineering based on metabolomics confers acetic and formic acid tolerance to a recombinant xylose-fermenting strain of Saccharomyces cerevisiae. Microb Cell Fact. 2011;10:2. doi:10.1186/1475-2859-10-2.

\section{Submit your next manuscript to BioMed Central and take full advantage of:}

- Convenient online submission

- Thorough peer review

- No space constraints or color figure charges

- Immediate publication on acceptance

- Inclusion in PubMed, CAS, Scopus and Google Scholar

- Research which is freely available for redistribution

Submit your manuscript at www.biomedcentral.com/submit 